\title{
Cost effectiveness of a controlled lifestyle intervention for pregnant women with obesity
}

Hanna Gyllensten ${ }^{1,2,3^{*}}$, Karin Haby ${ }^{1,4}$, Marie Berg ${ }^{1,2,5}$ and Åsa Premberg ${ }^{1,4}$

\begin{abstract}
Background: The Mighty Mums antenatal lifestyle intervention is a person-centered behavioral intervention focusing on nutrition and physical activity for pregnant women with obesity (body mass index [BMI] $\geq 30$ ). The aim of this study was to evaluate the costs and clinical outcomes of adding the Mighty Mums intervention to standard antenatal care.

Methods: Participants in the intervention group $(n=434)$ received motivational talks with their midwife and a selection of physical and/or nutritional activities in addition to antenatal care. Control participants $(n=867)$ from adjacent geographic areas received standard antenatal care. Costs for staff, unit costs for specific activities, and registered costs for specialized antenatal care were analyzed for associations with gestational weight gain and selfreported health. Results are reported for the intention-to-treat (ITT) population and a per protocol (PP) population identified by participation in the intervention. Analyses included bootstrapped linear regressions adjusted for background characteristics that differed significantly between groups.
\end{abstract}

Results: The average costs were SEK 9727 higher (95\% confidence interval [Cl]: 6677 to 12,777) among participants in the intervention group than in the control ITT population and SEK 8655 (95\% Cl 4586 to 12,724) higher than in the PP population. The cost increase per $1 \mathrm{~kg}$ reduction in gestational weight gain was SEK 12,369 in the ITT population and SEK 7209 for the PP population.

Conclusion: Participation in the Mighty Mums intervention was associated with higher costs, but also reduced gestational weight gain. The cost per kilogram reduction in gestational weight gain was low, particularly in the PP population. A future decision to implement this behavioral intervention in standard care should take into account society's willingness to pay per unit reduction in gestational weight gain.

Trial registration: The study is registered at ClinicalTrials.gov, Identifier: NCT03147079.

Keywords: Obesity, Pregnancy, Maternal health services, Diet, Food, And nutrition, Physical activity, Economic evaluation, Gestational weight gain

\footnotetext{
* Correspondence: hanna.gyllensten@gu.se

'Institute of Health and Care Sciences, University of Gothenburg, Box 457,

SE-405 30, Göteborg, Sweden

${ }^{2}$ Centre for Person-Centred Care - GPCC, University of Gothenburg,

Gothenburg, Sweden

Full list of author information is available at the end of the article
}

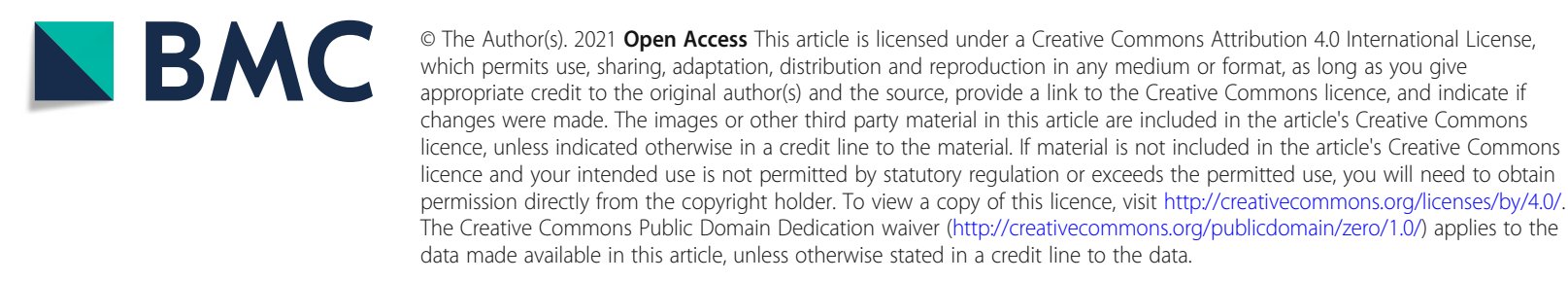




\section{Background}

Maternal obesity is associated with both increased risk of complications for mothers and children [1] and increased healthcare costs $[2,3]$ Women with obesity have higher risks than other women for gestational diabetes, pre-eclampsia, gestational hypertension, depression, instrumental or cesarean birth, preterm birth, large-forgestational-age babies, fetal defects, congenital anomalies, and perinatal death, lower rates of breastfeeding initiation, and greater risk of early breastfeeding cessation [4]. A recent literature review reported that the incremental costs (i.e., the difference in costs between those with and without the condition) of obesity during pregnancy ranges from EUR 191 to EUR 16,046, indicating large differences in costs between countries and the conditions included in individual studies [5].

In addition to complications during pregnancy, children of mothers who were obese before pregnancy are at increased risk of all-cause hospitalizations during their first 5 years [6]. Chronic diseases such as cardiovascular disease, metabolic syndrome, and type 2 diabetes later in the child's life have been associated with the mother's obesity during pregnancy [1]. In Europe, it is possible to distinguish a gradient in the prevalence of obesity in children under 10 years, which varies from $10 \%$ in the north of Europe to up to $40 \%$ in the south [7]. Risks associated with obesity in children span a wide range of biological, social, and environmental factors [8], including regional factors such as human development index and average income in the area of residence [9]. Among the main risk factors for obesity in children is parental BMI [10], and an additive effect of obesity and diabetes during pregnancy has been reported in both maternal health outcomes during pregnancy and child health after birth [11].

Knowledge of effective interventions to reduce the negative effects of obesity during pregnancy is insufficient [12]. Previous bariatric surgery has been shown to reduce a number of complications in obese mothers during pregnancy, such as gestational diabetes, hypertensive disorders, and macrosomia [13], but it is also associated with surgical and internal adverse outcomes (including nutrient deficiency) during pregnancy [12]. Supervised exercise and counseling about home exercise has also shown positive results in overweight women [14]. Overall, behavioral interventions, particularly diet-based interventions [15], appear to be effective in reducing gestational weight gain in obese women during pregnancy $[16,17]$. Variations in tested interventions make comparisons difficult [18], but interventions to reduce gestational weight gain have been reported to reduce costs and adverse health outcomes [19].

We previously demonstrated that the Mighty Mums person-centered behavioral intervention decreased gestational weight gain among pregnant women with obesity [20]. Person-centered care has been suggested as a way to involve patients in their own health decisions [21], which may be particularly important in primary healthcare, including antenatal care and lifestyle interventions. Healthcare decision-making should, however, also consider the cost effectiveness of new programs, since resources are scarce [22]. The aim of this study was to evaluate the costs associated with the clinical outcomes of including the Mighty Mums intervention in standard antenatal care.

\section{Methods}

\section{Study population}

We conducted a controlled trial in 2011 to 2013 to evaluate the Mighty Mums intervention, a behavioral antenatal care intervention aimed at pregnant women with BMI $\geq 30$, in Gothenburg, Sweden [20, 23].

The intervention group $(n=459)$ was recruited from antenatal care services in the Gothenburg area, with a source population of approximately 2500 pregnant women with $\mathrm{BMI} \geq 30$ during the study period. A group of internal controls $(n=105)$ were recruited from a source population of approximately 800 in other antenatal care units in the same geographic area. Women eligible for participation, in either the intervention or internal control groups, were informed about the study and asked for consent to participate by their midwife during their first visit to the antenatal care. To avoid biased results from only highly motivated women participating in either the intervention or the internal control group, the intervention was delivered through the standard antenatal care system. After informed consent, participants were followed during pregnancy and until postpartum checkup through register data and data collected specifically for the study. Women were excluded from the analyses if the pregnancy ended in abortion or miscarriage or if the first antenatal care visit occurred later than week 20. An external control group $(n=790)$ was identified in an adjacent geographic area and followed using register data covering all pregnant women of BMI $\geq 30$ in the register from that area. Register data were retrieved from the Swedish Maternity Health Care Register [24]. An overview of the inclusion process is presented in the study flow diagram (Additional file 1: Fig. S1).

Participation in other parallel interventions was a reason for exclusion from the intervention and internal control groups, but we had no information about such participation in the external controls.

\section{The antenatal care and the behavioral intervention}

All participants (the intervention group, internal controls, and external controls) received standard antenatal 
care which included midwife care during pregnancy and postpartum visits 2 to 3 months after childbirth-usually a total of 11 to 12 visits [25, 26]. In Sweden, antenatal care is midwife-driven, provided free of charge to all pregnant women and includes regular health checks, screening, psychological support, and education [27].

The intervention involved midwives using motivational interviewing [28] and person-centered care [21]. Women in the intervention group were scheduled to receive two extra appointments with the midwife. Motivational talks, personalized counselling on food and physical activity were added to the visit to the midwife, as well as followup on the woman's goals and progress throughout the pregnancy. They were also offered participation in activities (sub-interventions) directed toward nutrition and physical activity and able to use these according to their personal choices. Sub-interventions included visits with a dietician, individually or in group, aqua aerobics, walking poles, and pedometers as well as prescribed physical activity and information about lifestyle activities in community health centers. The information on physical activity and healthy eating was delivered by the midwife during the extra appointments at the beginning of the pregnancy, and about $5 \mathrm{~min}$ of each appointment during the pregnancy were dedicated to lifestyle follow-up and support. Adherence was monitored until postpartum checkup in a logbook designed for the Mighty Mums Project. Specific information about prescribed physical activities, associated contacts, and/or the use of community health centers was not available for the analyses. The women in the intervention group were encouraged to gain less than $7 \mathrm{~kg}$ during pregnancy.

\section{Health outcomes}

The primary health outcome measure of the study was gestational weight gain from enrollment to last pregnancy visit (weight reported to the Maternity Health Care Register). Change in self-rated health between enrollment and postpartum checkup was also reported to provide a broader perspective of health effects of the intervention.

\section{Costs}

The cost calculation was prevalence-based and included costs from enrolment to postpartum checkup for each participant (i.e., approximately 9 months), covering the relevant costs and the health outcomes. Studied costs included antenatal care visits, intervention participants' personalized use of sub-interventions, tests related to suspected complications, specialized antenatal care for occurring complications, and childbirth. Childbirth costs were calculated based on Robson groups, a classification system for births that is based on maternal and childbirth characteristics [29], and for which there is regional cost statistics available [30]. Interpreter costs were reported separately since a high number of intervention participants used interpreter services [20], which should be viewed more as an indicator of the broad recruitment rather than a cost resulting from the intervention. Costs for each resource are described in Table 1 . Because of the short time horizon, no discounting was conducted. Costs were adjusted for inflation using a national inflation factor for healthcare wages, excluding costs for drugs [32].

Complications in mothers resulting in specialized antenatal care included decreased glucose tolerance, gestational diabetes, gestational hypertension, and preeclampsia. For women with specialized antenatal care, costs were retrieved from an administrative register at the hospital (ELVIS register). Register costs were assumed to include the costs for childbirth if inpatient care costs were SEK 20,000 or more. A sensitivity analysis was conducted in which inpatient costs of SEK 15,000 or SEK 10,000 were also assumed to include costs during childbirth to add more conservative estimates for specialized healthcare costs.

Costs were not calculated for routine encounters and tests conducted by assistant nurses, as these were not registered in all antenatal care units. However, these services were assumed to be used to the same extent by participants in the intervention and standard care groups. The same applies for physician visits in antenatal care units.

Costs for conducting the controlled trial were reported separately, including costs for designing the study and educating participating midwifes and other antenatal healthcare professionals (based on $4 \mathrm{~h}$ each at a mean wage of SEK 345/h for 80 educators and participants).

\section{Analyses}

Imputation analyses using fully conditional specifications were conducted for missing data on postpartum weight, self-reported health, and antenatal care visits (seed for imputation: 4918 [20];. Predictive means matching was used for the imputation of antenatal care visits. The covariates included in the imputation of postpartum weight and self-reported health were baseline and postpartum measures, height, parity, age at enrolment, country of birth, use of interpreter, education, occupation, and use of nicotine [20]. The imputation of antenatal care visits included the numbers of visits registered in Swedish Maternity Health Care Register, numbers of postpartum visits, parity, pregnancy weeks, number of weeks past 40 weeks at birth, weight at enrollment (transformed to week 15 weight if enrollment occurred after week 15 using a national algorithm [33]; occupation, the mother's country of birth, and use of interpreter services. 
Table 1 Resource use and unit costs for each resource for intervention and control groups

\begin{tabular}{|c|c|c|c|c|c|c|}
\hline \multirow[t]{3}{*}{ RESOURCE } & \multirow[t]{3}{*}{ UNIT } & \multirow{3}{*}{$\begin{array}{l}\text { PRICE } \\
\text { SEK }\end{array}$} & \multicolumn{2}{|l|}{ ITT POPULATION } & \multicolumn{2}{|l|}{ PP POPULATION } \\
\hline & & & Intervention & Control & Intervention & Control \\
\hline & & & $N=434$ & $N=867$ & $N=115$ & $N=841$ \\
\hline \multicolumn{7}{|l|}{ ANTENATAL CARE VISITS } \\
\hline Midwife, first two visits & $45 \mathrm{~min}$ & $345 / h^{a}$ & 868 visits & 1734 visits & 230 visits & 1682 visits \\
\hline Midwife, subsequent visits & $30 \mathrm{~min}$ & $345 / h^{a}$ & $\begin{array}{l}4159 \text { visits } \\
\text { (mean: 9.6) }\end{array}$ & $\begin{array}{l}8201 \text { visits } \\
\text { (mean: } 9.5 \text { ) }\end{array}$ & $\begin{array}{l}1195 \text { visits } \\
\text { (mean: 10.4) }\end{array}$ & $\begin{array}{l}8024 \text { visits } \\
\text { (mean: } 9.5 \text { ) }\end{array}$ \\
\hline Midwife, post-natal visit & $30 \mathrm{~min}$ & $345 / h^{a}$ & 362 visits & 767 visits & 107 visits & 755 visits \\
\hline Physician & NA & & & & & \\
\hline Interpreter & & 550/h + 100/visit [31] & $\begin{array}{l}45 \text { women/ } \\
557 \text { visits }\end{array}$ & $\begin{array}{l}17 \text { women/ } \\
199 \text { visits }\end{array}$ & $\begin{array}{l}14 \text { women/ } \\
183 \text { visits }\end{array}$ & $\begin{array}{l}17 \text { women/ } \\
199 \text { visits }\end{array}$ \\
\hline \multicolumn{7}{|l|}{ SUB-INTERVENTIONS } \\
\hline $\begin{array}{l}\text { Individualized dietary advice from a } \\
\text { dietitian }\end{array}$ & $60 \mathrm{~min}$ & $310 / h^{a}$ & $\begin{array}{l}69 \text { women/ } \\
83 \text { visits }\end{array}$ & $\begin{array}{l}20 \text { women/ } \\
31 \text { visits }\end{array}$ & $\begin{array}{l}16 \text { women/ } \\
18 \text { visits }\end{array}$ & $\begin{array}{l}16 \text { women/ } \\
24 \text { visits }\end{array}$ \\
\hline Food discussion groups led by a dietitian & $\begin{array}{l}90 \text { min, } 5 \\
\text { participants }\end{array}$ & $310 / h^{a}$ & $\begin{array}{l}62 \text { women/ } \\
145 \text { visits }\end{array}$ & NA & $\begin{array}{l}26 \text { women/ } \\
59 \text { visits }\end{array}$ & NA \\
\hline Walking poles & 1 pair & 183/pair & 86 women & NA & 34 women & NA \\
\hline Pedometers & 1 unit & 60/unit & 148 women & NA & 45 women & NA \\
\hline $\begin{array}{l}\text { Information about community health } \\
\text { centers offering lifestyle education }\end{array}$ & Not listed & & Unknown & NA & Unknown & NA \\
\hline Aqua aerobics & $\begin{array}{l}60 \text { min (mean } 4.86 \\
\text { participants) }\end{array}$ & $\begin{array}{l}1000^{\mathrm{b}} \text { per maximum } \\
10 \text { participants }\end{array}$ & $\begin{array}{l}74 \text { women/ } \\
532 \text { visits }\end{array}$ & NA & $\begin{array}{l}25 \text { women/ } \\
214 \text { visits }\end{array}$ & NA \\
\hline Midwife & $60 \mathrm{~min}$ & $345 / h^{a}$ & 146 events & NA & - & NA \\
\hline SPECIALIZED ANTENATAL CARE & & & 54 women & 99 women & 9 women & 98 women \\
\hline Mother's complications ${ }^{c}$ & mother & From ELVIS ${ }^{d}$ & $53(12.2 \%)$ & $103(11.9 \%)$ & $9(7.8 \%)$ & $102(12.1 \%)$ \\
\hline Childbirth & mother & Published $^{e}$ & 434 & 867 & 115 & 841 \\
\hline Child's complications & child & Unknown & $91(21.0 \%)$ & $177(20.4 \%)$ & $21(18.3 \%)$ & $163(19.4 \%)$ \\
\hline
\end{tabular}

SEK Swedish krona, ITT Intention-to-treat, PP Per protocol.

${ }^{a}$ Average wage, including costs for professional development and continuing education.

${ }^{\mathrm{b}}$ Template cost varied somewhat during the study period based on number of participants and fees.

Includes gestational diabetes, gestational hypertension, and pre-eclampsia.

dindividual-level information collected from the administrative registers (ELVIS) at the local specialized antenatal care unit.

eMean cost by Robson group, identified using information about Cesarean section and parity [30].

Analyses were conducted both for the total study population and for a subset reported to have received the intervention PP [20], including at least three (out of seven) notes in the logbook of at least partly completed nutritional and physical activities. Maximum attendance in the intervention would imply seven visits with the midwife (i.e., seven occasions when the pregnant woman and her midwife discussed the intervention) and high adherence to the planned participation. Reporting both intention-to-treat results, including all included participants, and PP analyses selecting out those actually participating at a high level, allows better understanding of the effectiveness and efficacy of the intervention [34]. Moreover, PP participation required at least to have contributed with height and weight at enrollment, and weight at the end of pregnancy (thus, no imputation of the primary outcome was necessary).

The average costs per person (i.e., per pregnancy) were calculated from the resources used by each person, including antenatal care and tests for suspected complications, the intervention, and care for complications. Costs were reported as total average cost per person and by sociodemographic factors (age and BMI at enrolment, education, occupation, and smoking before pregnancy). All between-group differences, proportions, and means were tested for statistical significance $(P<0.05)$. Because of the skew in the data, confidence intervals $(\mathrm{CIs})$ were calculated using a bootstrap methodology [35], and differences were thus calculated using regression analyses with bootstrap. All adjusted analyses were conducted using country of birth, use of interpreter services, occupation, and BMI at enrollment as covariates.

The incremental cost-effectiveness ratio was calculated as the bootstrapped ratio of the difference in average total costs (excluding interpreter services) between intervention and control groups divided by the difference in gestational weight gain between the groups [36], thus indicating the cost for decreasing the gestational weight 
gain by 1 kilogram. As a sensitivity analysis, bootstrapped differences in costs and decreases in gestational weight gain were presented in a cost-effectiveness plane. Additionally, changes in self-reported health (Likert scale) were reported. ANOVA was used to examine the effect of intervention group and self-reported health at enrollment and postpartum. Ordered logistic regression was used to examine the effect of intervention group and self-reported health at enrollment on self-reported health postpartum, without and with adjustment for covariates. A sensitivity analysis of the cost distribution was conducted in the form of a tornado diagram, by calculating the mean total costs among groups of participants in the intervention group based on the subinterventions used, according to each individual's choices.

Analyses were conducted in Stata/SE 16.1 (StataCorp). Ethical approval for the study was received from the Regional Ethical Review Board in Gothenburg (\#505-10) in accordance with Helsinki declaration. The study has been registered at ClinicalTrials.gov, identifier: NCT03147079. 10/05/2017.

\section{Results}

\section{Characteristics of the study population}

A larger proportion of women in the intervention group had a BMI $\geq 40$ while a larger proportion of women in the control group were in the 30-35 BMI range (only in the ITT population) and/or were employed (Additional file 1: Table S1). As previously reported [20], it was also more common for women in the intervention group to be born in another country and to use interpreter services. Differences in the distribution of complications between groups were also reported (Additional file 1: Table S1).

The proportions of women with complications expected to result in specialized antenatal care were similar in the intervention and control groups (intervention: 54 [12\%]; control: 99 [11\%]). However, for $383(88 \%)$ of intervention group participants, and 814 (94\%) of controls, the hospital register did not include any specialized antenatal care. This indicates control group participants were to a larger extent not visiting the specific hospitals, from which data was available in this study, during complications.

\section{Cost outcomes}

After adjusting for background characteristics that differed significantly between groups, average costs were SEK 9727 (95\% CI: 6677 to 12,777; unadjusted: SEK 10,385, 95\% CI: 7490 to 13,280) higher among participants in the intervention group than in the control group (Table 2). Including interpreter services resulted in similar results (adjusted: SEK 9717; 95\% CI: 6667 to
12,767; unadjusted: SEK 9966; 95\% CI: 7088 to 12,845) in the ITT comparison. The unadjusted mean difference in costs for specialized antenatal care was SEK 7101 ( $95 \%$ CI: 4163 to 10,038), with higher costs for the intervention group. Limiting the analyses to participants adhering to the protocol (PP), we found that the cost difference was SEK 8953 (95\% CI: 4915 to 12,991) or SEK 8655 (95\% CI: 4586 to 12,724) after adjustment (Table 2).

Mean intervention costs (ITT) were SEK 5359 (95\% CI: 4406 to 6311). However, this varied from SEK 688 (95\% CI: -4093 to 5469 ) among those with BM I $\geq 40$ to SEK 6644 (95\% CI: 4316 to 8972) among with BMI 3540 at enrollment (Additional file 1: Table S2).

Educating participating midwifes and other antenatal care healthcare professionals resulted in additional costs of SEK 110,400 for conducting the Mighty Mums intervention.

\section{Health outcomes}

As previously reported [20], the Mighty Mums intervention program resulted in a lower gestational weight gain if comparing participants in the intervention group to those in the control group, using the ITT population (unadjusted difference: -0.9 [95\%CI: -1.7 to -0.2$] \mathrm{kg}$; adjusted difference: -0.2 [95\% CI: -1.0 to 0.6$] \mathrm{kg}$ ). Corresponding results for the PP population were unadjusted difference: -2.3 (95\% CI: -3.5 to -1.2$) \mathrm{kg}$, and adjusted difference: -1.5 (95\% CI: -2.6 to -0.3$) \mathrm{kg}$ (Additional file 1: Table S2). Self-reported health is reported in Additional file 1: Fig. S2. Self-reported postpartum health was higher among controls in unadjusted analyses for the ITT population $(P=0.024)$, but not in the adjusted analyses $(P=0.073)$ or in the PP analyses $(P=0.299$ unadjusted and $P=0.402$ adjusted).

\section{Cost effectiveness}

The incremental cost-effectiveness ratio was SEK 11,004 per $1 \mathrm{~kg}$ reduction in gestational weight gain in the ITT population. The corresponding result for the PP population was SEK 3841.

\section{Sensitivity analyses}

The cost-effectiveness plane is shown in Fig. 1, with a hypothetical threshold value of SEK $10,000 / \mathrm{kg}$ reduction in gestational weight gain indicated by a dashed line.

According to the one-way sensitivity analysis, the cost outcomes among participants in the intervention group were more sensitive to adverse pregnancy outcomes and the background characteristics of the participants than those directly affected by the intervention (Fig. 2). 
Table 2 Average costs (SEK) by cost components for different population groups and the differences between groups

\begin{tabular}{|c|c|c|c|c|c|c|}
\hline \multirow{3}{*}{$\begin{array}{l}\text { Background } \\
\text { characteristics }\end{array}$} & \multicolumn{3}{|l|}{ ITT population } & \multicolumn{3}{|l|}{ PP population } \\
\hline & Intervention & Controls & Difference & Intervention & Controls & Difference \\
\hline & $\begin{array}{l}\text { Mean } \\
(95 \% \mathrm{Cl})\end{array}$ & $\begin{array}{l}\text { Mean } \\
(95 \% \mathrm{Cl})\end{array}$ & $\begin{array}{l}\text { Unadjusted } M(95 \% \mathrm{Cl}) \\
\text { Adjusted } M(95 \% \mathrm{Cl}) \dagger\end{array}$ & $\begin{array}{l}\text { Mean } \\
(95 \% \mathrm{Cl})\end{array}$ & $\begin{array}{l}\text { Mean } \\
(95 \% \mathrm{Cl})\end{array}$ & $\begin{array}{l}\text { Unadjusted } M \\
(95 \% \mathrm{Cl}) \\
\text { Adjusted } M \\
(95 \% \mathrm{Cl})^{\mathrm{a}}\end{array}$ \\
\hline $\begin{array}{l}\text { Total cost, including } \\
\text { interpreter services }\end{array}$ & $\begin{array}{l}43,691(41,073 \\
\text { to } 46,309)\end{array}$ & $\begin{array}{l}33,306(32,180 \\
\text { to } 34,433)\end{array}$ & $\begin{array}{l}10,385(7490 \text { to } 13,280) \\
9727(6677 \text { to } 12,777)\end{array}$ & $\begin{array}{l}42,707(38,823 \\
\text { to } 46,590)\end{array}$ & $\begin{array}{l}33,218(32,109 \\
\text { to } 34,327)\end{array}$ & $\begin{array}{l}9489 \text { (5450 to } \\
13,528) \\
8693 \text { (4627 to } \\
12,758)\end{array}$ \\
\hline Interpreter & 510 (362 to 658$)$ & 91 (47 to 136$)$ & $\begin{array}{l}418 \text { (265 to } 572) \\
10(-13 \text { to } 33)\end{array}$ & 630 (329 to 932) & 94 (50 to 139$)$ & $\begin{array}{l}536(222 \text { to } \\
850) \\
38(-9 \text { to } 85)\end{array}$ \\
\hline $\begin{array}{l}\text { Total cost, excluding } \\
\text { interpreter services }\end{array}$ & $\begin{array}{l}43,181(40,578 \\
\text { to } 45,784)\end{array}$ & $\begin{array}{l}33,215(32,089 \\
\text { to } 34,341)\end{array}$ & $\begin{array}{l}9966(7088 \text { to } 12,845) \\
9717(6667 \text { to } 12,767)\end{array}$ & $\begin{array}{l}42,076(38,206 \\
\text { to } 45,947)\end{array}$ & $\begin{array}{l}33,124(32,018 \\
\text { to } 34,229)\end{array}$ & $\begin{array}{l}8953(4915 \text { to } \\
12,991) \\
8655(4586 \text { to } \\
12,724)\end{array}$ \\
\hline \multicolumn{7}{|l|}{ Antenatal and childbirth costs } \\
\hline Antenatal midwife visits & $\begin{array}{l}2314 \text { (2261 to } \\
2367)\end{array}$ & $\begin{array}{l}2302 \text { (2265 to } \\
2339)\end{array}$ & $\begin{array}{l}13(-50 \text { to } 76) \\
30(-35 \text { to } 95)\end{array}$ & $\begin{array}{l}2471 \text { (2383 to } \\
2558)\end{array}$ & $\begin{array}{l}2318(2281 \text { to } \\
2356)\end{array}$ & $\begin{array}{l}152(51 \text { to } 253) \\
176 \text { (75 to } 277)\end{array}$ \\
\hline Hospital-based care & $\begin{array}{l}34,333(31,862 \\
\text { to } 36,804)\end{array}$ & $\begin{array}{l}30,157(29,078 \\
\text { to } 31,253)\end{array}$ & $\begin{array}{l}4177 \text { (1447 to } 6907) \\
4784 \text { (1866 to } 7703)\end{array}$ & $\begin{array}{l}32,296(28,719 \\
\text { to } 35,873)\end{array}$ & $\begin{array}{l}30,180(29,107 \\
\text { to } 31,253)\end{array}$ & $\begin{array}{l}2116(-1666 \text { to } \\
5897) \\
2348(-1438 \text { to } \\
6134)\end{array}$ \\
\hline $\begin{array}{l}\text { Specialized antenatal } \\
\text { care }^{b}\end{array}$ & $\begin{array}{l}9415(6552 \text { to } \\
12,278)\end{array}$ & $\begin{array}{l}2314 \text { (1570 to } \\
3058)\end{array}$ & $\begin{array}{l}7101(4163 \text { to } 10,038) \\
7706(4583 \text { to } 10,829)\end{array}$ & $4821(899-8742)$ & $\begin{array}{l}2356 \text { (1624 to } \\
3087)\end{array}$ & $\begin{array}{l}2465(-1180 \text { to } \\
-6110) \\
2874(-800 \text { to } \\
-6548)\end{array}$ \\
\hline Childbirth $^{\mathrm{b}}$ & $\begin{array}{l}24,918(23,561 \\
\text { to } 26,276)\end{array}$ & $\begin{array}{l}27,842(26,893 \\
\text { to } 28,791)\end{array}$ & $\begin{array}{l}-2924(4587 \text { to }-1261) \\
-2922(-4653 \text { to }-1190)\end{array}$ & $\begin{array}{l}27,475(24,885 \\
\text { to } 30,066)\end{array}$ & $\begin{array}{l}27,825(26,913 \\
\text { to } 28,736)\end{array}$ & $\begin{array}{l}-349(-3088 \\
\text { to } 2389) \\
-546(-3436 \\
\text { to } 2384)\end{array}$ \\
\hline \multicolumn{7}{|l|}{ Intervention costs } \\
\hline $\begin{array}{l}\text { Food discussion groups } \\
\text { led by a dietitian }\end{array}$ & $\begin{array}{l}1864 \text { (1420 to } \\
2309)\end{array}$ & 0 & $\begin{array}{l}1864(1392 \text { to } 2336) \\
2114(1584 \text { to } 2645)\end{array}$ & $\begin{array}{l}2863 \text { (1788 to } \\
3938)\end{array}$ & 0 & $\begin{array}{l}2863 \text { (1803 to } \\
3923) \\
3079 \text { (1967 to } \\
4190)\end{array}$ \\
\hline $\begin{array}{l}\text { Individualized dietary } \\
\text { advice from a dietitian }\end{array}$ & $\begin{array}{l}3557 \text { (2686 to } \\
4428)\end{array}$ & $\begin{array}{l}665(327 \text { to } \\
1004)\end{array}$ & $\begin{array}{l}2892 \text { (1986 to } 3798) \\
2098 \text { (1283 to } 2914)\end{array}$ & $\begin{array}{l}2911 \text { (1441 to } \\
\text { 4382) }\end{array}$ & 531 (243 to 819) & $\begin{array}{l}2381 \text { (869 to } \\
3892) \\
2051 \text { (689 to } \\
3412 \text { ) }\end{array}$ \\
\hline Pedometers & 20 (18 to 23$)$ & 0 & $\begin{array}{l}20(18 \text { to } 23) \\
20(18 \text { to } 23)\end{array}$ & 23 (18 to 29$)$ & 0 & $\begin{array}{l}23(18 \text { to } 29) \\
23(18 \text { to } 29)\end{array}$ \\
\hline Walking poles & 36 (29 to 43$)$ & 0 & $\begin{array}{l}36(30 \text { to } 43) \\
37(30 \text { to } 44)\end{array}$ & 54 (39 to 69) & 0 & $\begin{array}{l}54(39 \text { to } 69) \\
55(39 \text { to } 70)\end{array}$ \\
\hline Aqua aerobics & 545 (401 to 690$)$ & 0 & $\begin{array}{l}545 \text { (398 to } 693) \\
622(456 \text { to } 788)\end{array}$ & $\begin{array}{l}828(483 \text { to } \\
1173)\end{array}$ & 0 & $\begin{array}{l}828(478 \text { to } \\
1177) \\
886(522 \text { to } \\
1249)\end{array}$ \\
\hline
\end{tabular}

CI Confidence interval, ITT Intention-to-treat, PP Per protocol, SEK Swedish krona.

Figures are rounded.

${ }^{a}$ Adjusted for country of birth, use of interpreter services, occupation, and BMI at enrolment.

${ }^{b}$ For 63 participants, specialized antenatal care records included inpatient care over SEK 20,000, which was assumed to include costs for childbirth and thus were not included as template costs based on Robson group.

Conversely, gestational weight gain (Fig. 3) was mainly sensitive to BMI categories. No statistically significant effect of self-reported health was found for costs $(P>0.3$ in both ITT and PP analyses).

\section{Discussion}

Healthcare costs were approximately SEK 10,000 higher among women receiving the Mighty Mums intervention as an add-on to antenatal care than among women 


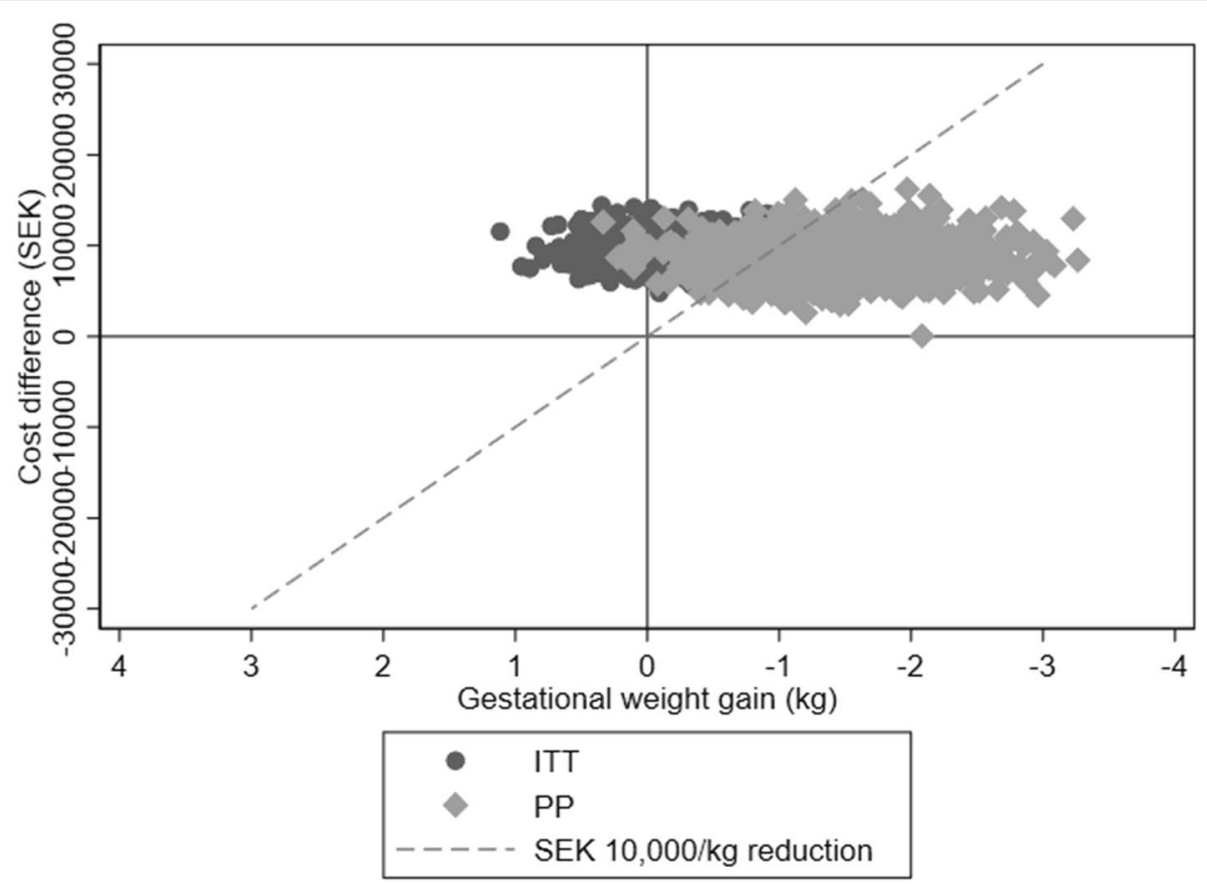

Fig. 1 Incremental cost-effectiveness plane of the Mighty Mums intervention (adjusted analyses). ITT=intention to treat; PP= per protocol; SEK= Swedish krona. The $\mathrm{x}$-axis is inverted to ensure an assumed positive health outcome (i.e., reduced gestational weight gain) is shown to the right in the figure

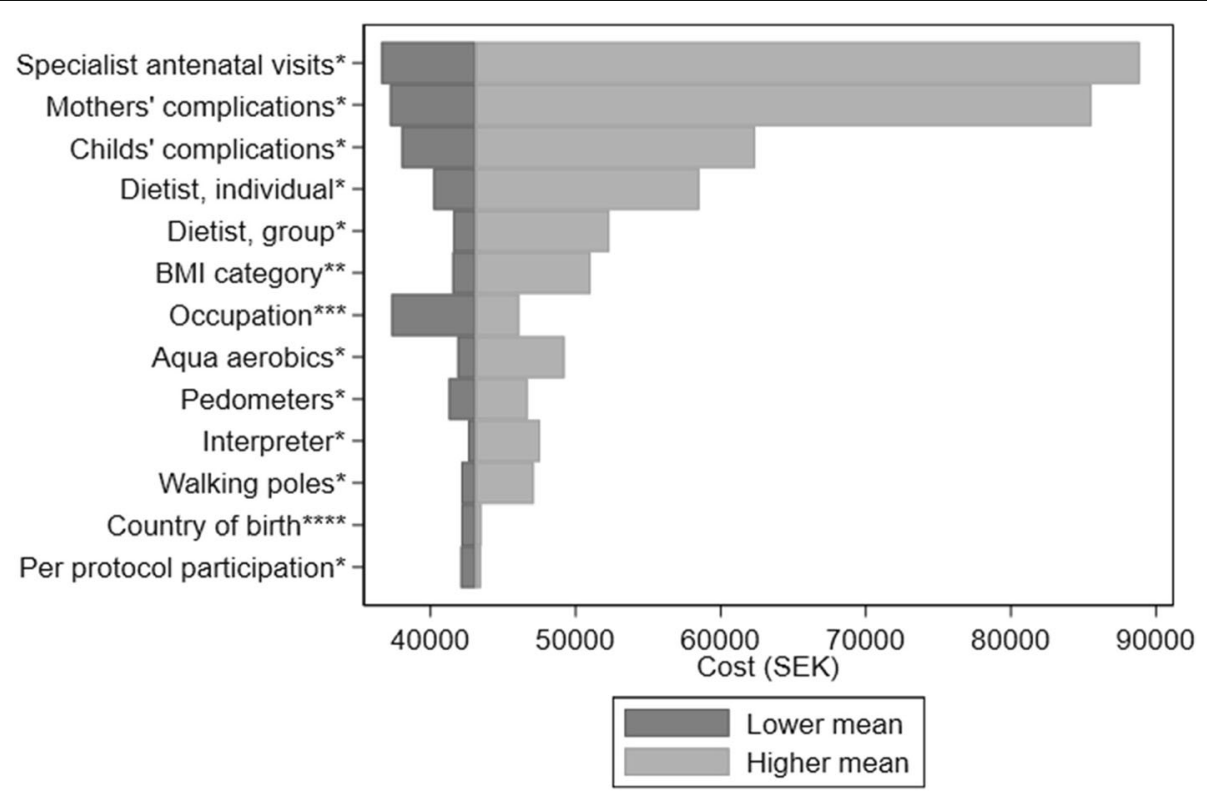

Fig. 2 Univariate analysis of the distribution of mean costs (excluding interpreter services) by health outcomes and background characteristics of participants in the Mighty Mums intervention group. BMI = body mass index; SEK = Swedish krona. Categories indicated by lower mean v. higher mean: ${ }^{*}$ No v. yes. ${ }^{* *}$ BMl $30-35$ v. BMI $\geq 40 .{ }^{* *}$ Other v. paid work. ${ }^{* * *}$ Sweden v. other 


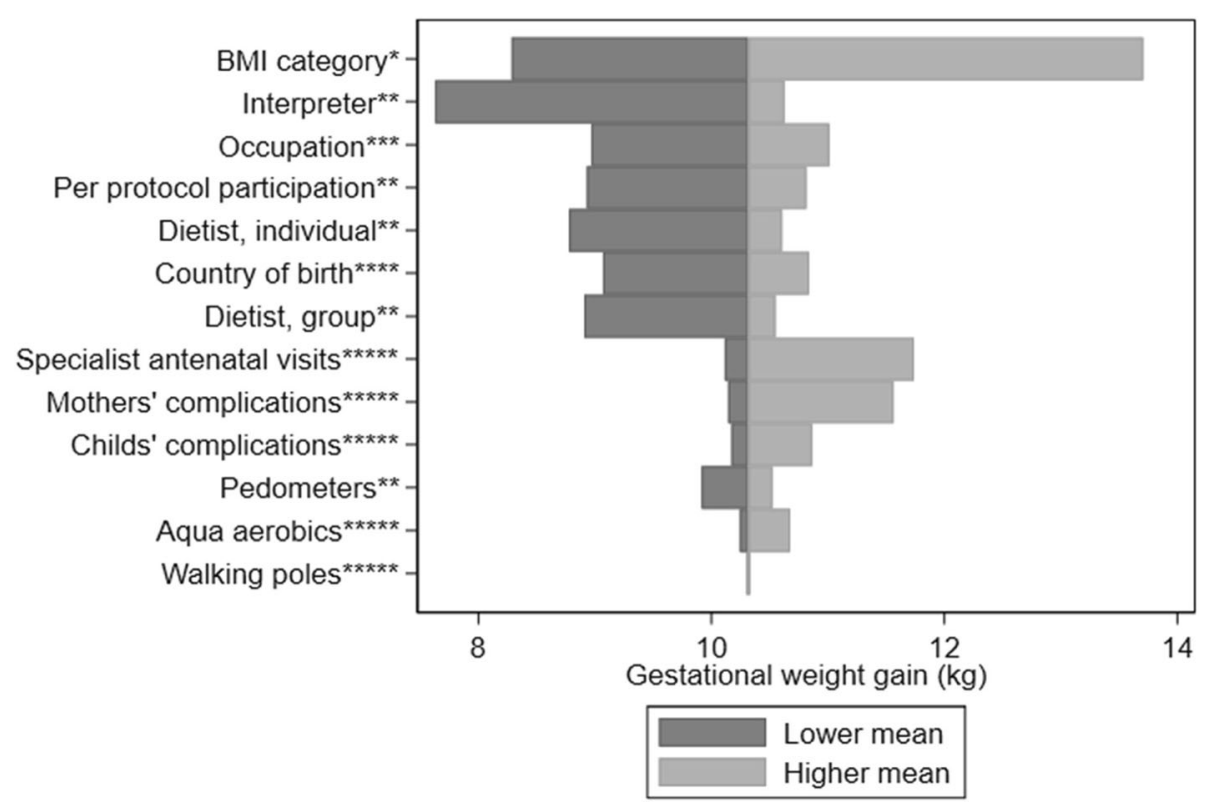

Fig. 3 Univariate analysis on the distribution of mean gestational weight gain by health outcomes and background characteristics of participants in the Mighty Mums intervention group. BMI = body mass index; $\mathrm{kg}=$ kilograms. Categories indicated by lower mean $\mathrm{v}$. higher mean: ${ }^{*} \mathrm{BMI} \geq 40$ v. BMl <30. ${ }^{* *}$ Yes v. no. ${ }^{* *}$ Other v. paid work. ${ }^{* * *}$ Sweden v. other. ${ }^{* * * *}$ No v. yes

receiving standard antenatal care. The cost per kilogram reduction in gestational weight gain was SEK 11,004, but the cost was considerably lower if only the PP population was analyzed (SEK 3841). These estimates correspond to (unadjusted/adjusted mean values) EUR 907/ EUR 884 higher overall costs for participants in the intervention, and a corresponding incremental costeffectiveness ratio of EUR 1001 per kilogram reduction in gestational weight gain in the ITT population, and EUR 349 in the PP population, inflated to 2018 values [32] and converted to EUR using purchasing power parities [37]. However, differences in background characteristics between the groups, such as BMI at enrollment appear to have affected health outcomes. Moreover, costs appear to have been mainly sensitive to complications. Limitations in the data collection make it unfeasible do draw conclusive results regarding the costs of complications.

Major strengths of the study were the populationbased approach and delivery through standard antenatal care, which could allow the effects to be identified as relevant and applicable to standard antenatal care. The main limitation, however, was the lack of randomization and low recruitment of participants for the internal control group, which negatively affects the generalizability of results. Although the sociodemographic background in the studied geographic areas were expected to be similar, the resulting intervention group included an unexpectedly higher proportion of women needing interpreter services than in women in the control group. In the analyses, the costs for interpreter services were thus reported separately. In addition to causing extra costs in antenatal care, such differences in background characteristics could potentially result in additional costs for healthcare overall, which was not possible to derive using the retrospectively collected data used in this study. It has previously been reported that immigrant women in Sweden have a higher risk of severe maternal morbidity [38], which has been partially explained by their higher likelihood to receive sub-optimal and negative care experiences [39]. The low recruitment may also have resulted in a selection of participants, especially in the internal control group, based on the midwives' and/ or the women's own motivations to participate. Concerns have been raised about how well the effect of behavioral interventions can be studied, as mothers choosing to enter a lifestyle intervention are likely to be more motivated to make changes to their lifestyle during pregnancy regardless of their randomization into the intervention or the control group [40]. Additionally, 20 women $(20 \%)$ of those in the internal control group (most with BMI > 40) received individualized dietary advice as part of their antenatal care, allowing the argument that these women received part of the intervention. In fact, these selected women did receive, on average, more encounters with the dietician than participants in the intervention (1.6 visits vs. 1.2 for those using this specific resource). Underpowering is common in so called "piggyback" economic evaluations, studies where the economic evaluation is added in a later stage 
as an add-on to the main study design, that sample sizes based on the clinical evaluation [41]. This mean that the sample size is not large enough to reject the null hypothesis of no difference between the groups. However, in addition to underpowering, the analyses in this study are also hindered by the quasi-experimental design and the apparently biased recruitment.

One limitation of our cost estimations was our use of Robson categories. Since no information was registered on breech presentation or induction of birth, the analyses could only take into account some of the factors affecting Robson group [29]. We thus underestimated the total costs of births in this study, since factors that could have resulted in births being listed in more costly Robson categories were unaccounted for. Additionally, when collecting data retrospectively from the hospital records, it was found that the register did not fully associate costs and specific health encounters, thus resulting in an inability to deduce whether costs for the specialized antenatal care included costs for the hospital admission during labor and delivery. In combination with apparent missing data on costs for specialized antenatal care for a group of participants in the control group, the increase in costs resulting from the intervention appears to be exaggerated. The dietitian group and individual meetings with a dietitian were the most expensive subinterventions in this study, but the costs for these services were also highly related to the number of people participating, and costs per participant could thus be decreased through increased participation if the program were provided to a larger population.

Our results are in line with a previous meta-analysis, which found that antenatal diet and physical activity interventions reduced gestational weight gain by an average of $0.7 \mathrm{~kg}$, but with no associated effects on complications [42]. A Cochrane review found similar results, but with possibly reduced risks of gestational diabetes mellitus and cesarean section [43]. We found no such reductions in our data, although the proportion with cesarean section was already lower in all studied groups $(20-23 \%)$ than in previously reported results (299 per 1000 and 284 per 1000, respectively [43];. This study used a person-centered approach, and thus the woman and her midwife jointly decided the balance between diet and exercise for each participant. The PP analysis included women who fulfilled their goals for both diet and exercise, but we do not know if that means the woman actively conducted both types of interventions as they would depend on the goals set. However, previous research suggests that both diet and exercise, in isolation, and the combination, all have shown beneficial effects during pregnancy [44, 45]. Thus, it is possible that there were women judged as not fulfilling the PP level who still performed well on either diet or exercise and had beneficial effects of the intervention. Applying stricter cut-offs for inclusion in the PP analyses also resulted in a trend toward even lower gestational weight gain (unpublished results), although at the cost of reduced sample size. The corresponding effect on costs was negligible. One possible interpretation is that the intervention had the expected effect on weight, and that the comparably higher costs in the intervention group were associated not with participation in the study but rather with data limitations. Moreover, the follow-up enabled personalized feedback and discussions about the individuals' performance and potential changes to the set goals. Individualized feedback appears to be an important factor in promoting healthy behavioral changes [46]. This study was not set up to examine long-term effects or costs. It is possible that an intervention such as this will affect behavior long-term, and thus potentially have beneficial effects on the future health of both mother and child. In our follow-up, when the children have reached 2.5 years of age (unpublished results), longterm analyses will be even more difficult, due to nonresponse, consecutive pregnancies, surgery, and other activities conducted to handle the obesity.

Although the Mighty Mums antenatal lifestyle intervention has demonstrated effectiveness in reducing gestational weight gain among those adhering to their set goals, limitations in data collection make conclusive estimates of its cost effectiveness challenging. Moreover, differences in characteristics and data availability between study groups make assessment of opportunity costs unfeasible. The additional cost for providing the intervention was small compared to the total cost for antenatal care in this patient group, and the cost for educating personnel and developing the intervention was about the same as caring for three pregnancies. The only components available to assess the costs of executing the intervention [47] was that of the midwives' additional education. No further assessment was made of costs for developing the intervention. It is possible that there were additional costs attached to both developing the intervention and implementing it in antenatal care, but those were not collected or possible to deduce retrospectively. Future studies should ensure all costs associated with implementing such interventions are explored, in accordance with recommended practices [47], Based on the available data, no conclusions can be drawn on how often the educational program needs to be repeated to ensure personnel are updated. However, it should be natural to include it in in-service training to carry out the guidelines for managing overweight and obesity in pregnancy. The person-centered aspects of the intervention reflect the transition in Swedish healthcare to meet patients on a more individual basis, and most regions are now committed to developing such partnerships with 
patients [48]. The findings regarding the subinterventions may be used to guide future initiatives. The costs varied between components from very small (e.g., for pedometers) to more resource intense activities such as dietician visits. However, the one-way sensitivity analyses indicate that at least some of the more resource-consuming activities (e.g., dietitian contacts and aqua aerobics) were more frequent among women who managed better to restrict their gestational weight gain.

Before introducing Mighty Mums or a similar intervention, evidence is needed of its potential beneficial effects on other aspects of care or the health of pregnant women with $\mathrm{BMI} \geq 30$, because current data indicate small effects on gestational weight gain and costs that are not negligible. To draw conclusions about the actual value of such an intervention, a value needs to be put on the potential health effects being measured. For example, what is the value, or how much is society willing to pay, for a specific decrease in gestational weight gain? This depends on what is the actual effect of decreasing gestational weight gain. This has also been discussed in a recent health economic evaluation of interventions to reduce gestational weight gain as part of decreasing gestational diabetes, in which the decided threshold was found to affect the cost effectiveness of said interventions [49]. The same applies to acceptable costs for reducing adverse maternal outcomes, such as gestational diabetes or hypertensive disease in pregnancy [50]. Thus, more research is needed on the long-term effects of decreasing gestational weight gain through antenatal care interventions, including their potential effects on health-related quality of life, to enable comparisons of cost effectiveness with other healthcare interventions. Moreover, future research needs to clarify whether pregnancy is a beneficial period to create change in healthy lifestyles, or if interventions should rather be offered before pregnancy or after birth.

\section{Conclusions}

The costs in pregnant women with obesity who participated in the Mighty Mums intervention were slightly higher than non-participants and a small proportion of the total cost of antenatal and perinatal care. Moreover, the cost per one-kilogram reduction in gestational weight gain was also fairly small, particularly among people who participated actively in the intervention. The results were sensitive to limitations in the retrospective data collection, however, resulting in underestimation of costs for specialized antenatal care, births, and complications, especially among controls. More research is needed to establish the actual value to decision-makers and patients of decreasing gestational weight gain, when such actions would be most beneficial in the long-term, and which interventions are most effective.

\section{Abbreviations}

BMI : Body mass index; PP : Per protocol; ITT: Intention to treat; SEK: Swedish krona

\section{Supplementary Information}

The online version contains supplementary material available at https://doi. org/10.1186/s12884-021-04098-5.

Additional file 1: Figure S1: Study flow chart. Table S1. Descriptive statistics for the ITT and PP study populations. Table S2. Average cost (SEK) and gestational weight gain (kg) from ITT and PP analysis, and differences by population groups. Figure S2: Distribution of self-reported health status during enrolment and postpartum visit among women participating in the Mighty Mums intervention and controls. Question in the Mighty Mums project relevant for this study.

\section{Acknowledgements}

The local Research and Development Board for Gothenburg and Södra Bohuslän, Gothenburg, Sweden, and Centre for Person-centred Care (GPCC), University of Gothenburg, Gothenburg, Sweden funded the study.

We thank Elisabeth Hansson Olofsson, who participated in the design of the economic analysis and discussed our preliminary results and drafts; Ragnar Hanås, who participated in the design and evaluation of clinical aspects of the intervention; our contacts at the Swedish Maternity Health Care Register and in the Region Västra Götaland/ELVIS, for guidance during the data collection; and the Statistical Consulting Group, Gothenburg, who conducted some of the data management and imputations.

Our heartfelt thanks go to the women who participated in the study and the midwives and other antenatal care staff who made this study possible.

\section{Authors' contributions}

K.H. designed and performed the intervention and collected all data from medical records and registers. H.G., K.H., M.B., and A.P. designed the economic evaluation study. H.G. and KH analysed the data, HG drafted the manuscript. H.G., K.H., M.B., and A.P. discussed the results and contributed to the manuscript. H.G., K.H., M.B., and Å.P. approved the final manuscript.

\section{Funding}

Funding was received from the local Research and Development Board for Gothenburg and Södra Bohuslän, Gothenburg, Sweden, and Centre for Person-centred Care (GPCC), University of Gothenburg, Gothenburg, Sweden. Open Access funding provided by University of Gothenburg.

\section{Availability of data and materials}

The study protocol, statistical analysis plan and informed consent form (all in Swedish) can be requested from the corresponding author. The individual data in this study are not publicly available. Data can only be available after legal review to researchers who meet the criteria for access to this type of sensitive and confidential data (in accordance with the Swedish Ethical Review Act, the Personal Data Act, and the Administrative Procedure Act).

\section{Declarations}

\section{Ethics approval and consent to participate}

Ethical approval for the study was received from the Regional Ethical Review Board in Gothenburg (\#505-10). All participant gave their informed consent and were informed of their ability to withdraw from the study at any time. The intervention was registered in ClinicalTrials.gov (project identifier: NCT03147079).

\section{Consent for publication}

All authors of the article have read the final manuscript and approved publication in this journal.

Competing interests

The authors state they have no conflicts of interest. 


\section{Author details}

'Institute of Health and Care Sciences, University of Gothenburg, Box 457, SE-405 30, Göteborg, Sweden. ${ }^{2}$ Centre for Person-Centred Care - GPCC, University of Gothenburg, Gothenburg, Sweden. ${ }^{3}$ Department of Clinical Neuroscience, Karolinska Institutet, Stockholm, Sweden. ${ }^{4}$ Region Västra Götaland, Research and Development Primary Health Care, Gothenburg, Sweden. ${ }^{5}$ Region Västra Götaland, Sahlgrenska University Hospital, Department of Obstetrics, Gothenburg, Sweden.

Received: 5 November 2020 Accepted: 29 August 2021 Published online: 21 September 2021

\section{References}

1. Galliano D, Bellver J. Female obesity: short- and long-term consequences on the offspring. Gynecol Endocrinol. 2013;29(7):626-31. https://doi.org/10.31 09/09513590.2013.777420.

2. Denison FC, Norwood P, Bhattacharya S, Duffy A, Mahmood T, Morris C, et al. Association between maternal body mass index during pregnancy, short-term morbidity, and increased health service costs: a populationbased study. BJOG. 2014;121(1):72-81discussion 82. https://doi.org/1 0.1111/1471-0528.12443.

3. Morgan KL, Rahman MA, Macey S, Atkinson MD, Hill RA, Khanom A, et al. Obesity in pregnancy: a retrospective prevalence-based study on health service utilisation and costs on the NHS. BMJ Open. 2014:4:e003983-2013003983

4. Marchi J, Berg M, Dencker A, Olander EK, Begley C. Risks associated with obesity in pregnancy, for the mother and baby: a systematic review of reviews. Obes Rev. 2015;16(8):621-38. https://doi.org/10.1111/obr.12288.

5. Moran PS, Wuytack F, Turner M, Normand C, Brown S, Begley C, et al. Economic burden of maternal morbidity - a systematic review of cost-ofillness studies. PLoS One. 2020;15(1):e0227377. https://doi.org/10.1371/ journal.pone.0227377.

6. Cameron CM, Shibl R, McClure RJ, Ng SK, Hills AP. Maternal pregravid body mass index and child hospital admissions in the first 5 years of life: results from an Australian birth cohort. Int J Obes (Lond). 2014;38(10):1268-74. https://doi.org/10.1038/ijo.2014.148.

7. Ahrens W, Pigeot I, Pohlabeln H, De Henauw S, Lissner L, Molnar D, et al. Prevalence of overweight and obesity in European children below the age of 10. Int J Obes (Lond). 2014;38(Suppl 2):S99-107. https://doi.org/10.1038/ ijo.2014.140.

8. Campbell MK. Biological, environmental, and social influences on childhood obesity. Pediatr Res. 2015;79:205-11.

9. Bammann K, Gwozdz W, Lanfer A, Barba G, De Henauw S, Eiben G, et al. Socioeconomic factors and childhood overweight in Europe: results from the multi-Centre IDEFICS study. Pediatr Obes. 2013;8(1):1-12. https://doi. org/10.1111/j.2047-6310.2012.00075.x.

10. Bammann K, Peplies J, De Henauw S, Hunsberger M, Molnar D, Moreno LA, et al. Early life course risk factors for childhood obesity: the IDEFICS casecontrol study. PLoS One. 2014;9(2):e86914. https://doi.org/10.1371/journal. pone.0086914

11. Whiteman VE, Salemi JL, Mejia De Grubb MC, Ashley Cain M, Mogos MF, Zoorob RJ, et al. Additive effects of pre-pregnancy body mass index and gestational diabetes on health outcomes and costs. Obesity. 2015;23(11): 2299-308. https://doi.org/10.1002/oby.21222.

12. Arabin B, Stupin JH. Overweight and obesity before, during and after pregnancy: part 2: evidence-based risk factors and interventions. Geburtshilfe Frauenheilkd. 2014;74(7):646-55. https://doi.org/10.1055/s0034-1368462

13. Yi XY, Li QF, Zhang J, Wang ZH. A meta-analysis of maternal and fetal outcomes of pregnancy after bariatric surgery. Int J Gynaecol Obstet. 2015; 130:3-9.

14. Nascimento S, Surita F, Parpinelli M, Siani S, Pinto e Silva J. The effect of an antenatal physical exercise programme on maternal/perinatal outcomes and quality of life in overweight and obese pregnant women: a randomised clinical trial. BJOG. 2011;118(12):1455-63. https://doi.org/10.1111/j.1471-052 8.2011.03084.x.

15. Thangaratinam $S$, Rogozinska E, Jolly K, Glinkowski S, Roseboom T, Tomlinson JW, et al. Effects of interventions in pregnancy on maternal weight and obstetric outcomes: meta-analysis of randomised evidence. BMJ. 2012;344(may16 4):e2088. https://doi.org/10.1136/bmj.e2088.
16. International Weight Management in Pregnancy (i-WIP) Collaborative Group. Effect of diet and physical activity based interventions in pregnancy on gestational weight gain and pregnancy outcomes: meta-analysis of individual participant data from randomised trials. BMJ. 2017;358:31119.

17. Tanentsapf I, Heitmann BL, Adegboye AR. Systematic review of clinical trials on dietary interventions to prevent excessive weight gain during pregnancy among normal weight, overweight and obese women. BMC Pregnancy Childbirth. 2011;11(1):81. https://doi.org/10.1186/1471-2393-11-81.

18. Agha M, Agha RA, Sandall J. Interventions to reduce and prevent obesity in pre-conceptual and pregnant women: a systematic review and metaanalysis. PLoS One. 2014;9(5):e95132. https://doi.org/10.1371/journal.pone. 0095132.

19. Caldas MC, Serrette JM, Jain SK, Makhlouf M, Olson GL, McCormick DP. Maternal morbid obesity: financial implications of weight management. Clin Obes. 2015;5(6):333-41. https://doi.org/10.1111/cob.12116.

20. Haby K, Berg M, Gyllensten H, Hanås R, Premberg Å. Mighty mums - a lifestyle intervention at primary care level reduces gestational weight gain in women with obesity. BMC Obes. 2018;5(1):16. https://doi.org/10.1186/s4 0608-018-0194-4.

21. Ekman I, Swedberg K, Taft C, Lindseth A, Norberg A, Brink E, et al. Personcentered care--ready for prime time. Eur J Cardiovasc Nurs. 2011;10(4):24851. https://doi.org/10.1016/j.ejcnurse.2011.06.008.

22. O'Reilly D, Gaebel K, Xie F, Tarride J-E, Goeree R. Health economic evaluations help inform payers of the best use of scarce health care resources. Int J Circumpolar Health. 2011;70(4):417-27. https://doi.org/10.34 02/ijch.v70i4.17843.

23. Haby K, Glantz A, Hanås R, Premberg Å. Mighty mums - an antenatal health care intervention can reduce gestational weight gain in women with obesity. Midwifery. 2015;31(7):685-92. https://doi.org/10.1016/j.midw.2015.03.014.

24. Petersson K, Persson M, Lindkvist M, Hammarstrom M, Nilses C, Haglund I, et al. Internal validity of the Swedish maternal health care register. BMC Health Serv Res. 2014;14(1):364. https://doi.org/10.1186/1472-6963-14-364.

25. Basprogram för graviditetsövervakning / hälsovård för gravida i Göteborg [Basic program for pregnancy monitoring / health care for pregnant women in Gothenburg]. Gothenburg: Region Västra Götaland: Centrala mödrahälsovårdsteamet Göteborg, Region Västra Götaland [Central Maternal Health Care Team, Gothenburg, Region Västra Götaland]; 2012.

26. Stephansson O, Petersson K, Björk C, Conner P, Wikström A-K. The Swedish pregnancy register - for quality of care improvement and research. Acta Obstet Gynecol Scand. 2018;97(4):466-76. https://doi. org/10.1111/aogs.13266.

27. Anell A, Glenngård AH, Merkur S. Sweden: health system review. Health Syst Transit. 2012;14:1-159.

28. Emmons KM, Rollnick S. Motivational interviewing in health care settings. Opportunities and limitations. Am J Prev Med. 2001;20:68-74.

29. World Health Organization. Robson classification: implementation manual. Geneva: World Health Organization; 2017. http://www.who.int/ reproductivehealth/publications/maternal_perinatal_health/robson-classifica tion/en/. Accessed 8 May 2020

30. Angerås U, Kjellström A, Ladfors L. Förlossningsvården i Västra Götalandsregionen 2002-2013 - med fokus på fullgångna förstföderskor [Childbirth care in the Västra Götaland region 2002-2013-Focusing on fulltime firstborns]. Hälso- och sjukvårdsavdelningen, Västra Götalandsregionen [Department of Health, Västra Götaland Region]; 2015.

31. Landstingens faktiska kostnader för Försäkringskassans beställningar. The county Council's actual costs for the social insurance Agency's orders. Stockholm: Socialstyrelsen: Socialstyrelsen; 2014.

32. Holm M. Löne- och prisförändringar för regioner 2018-2019 [wage and price developments in the regions]; 2020. https://skr.se/ekonomijuridiksta tistik/ekonomi/ekonominyttregioner/arkivekonominytt/ekonominytt2020/ 032020loneochprisforandringarforregioner20182019.32260.html. Accessed 4 Jun 2020

33. Johansson K, Hutcheon JA, Stephansson O, Cnattingius S. Pregnancy weight gain by gestational age and BMI in Sweden: a population-based cohort study. Am J Clin Nutr. 2016;103(5):1278-84. https://doi.org/10.3945/ajcn.11 5.110197.

34. Ranganathan P, Pramesh CS, Aggarwal R. Common pitfalls in statistical analysis: intention-to-treat versus per-protocol analysis. Perspect Clin Res. 2016;7(3):144-6. https://doi.org/10.4103/2229-3485.184823.

35. Barber JA, Thompson SG. Analysis of cost data in randomized trials: an application of the non-parametric bootstrap. Stat Med. 2000;19:3219-36. 
36. Gallacher D. HEABS: Stata module to calculate the ICER and net benefit for up to two datasets; 2020. Boston College Department of Economics; https:// ideas.repec.org/c/boc/bocode/s458438.html. Accessed 31 Mar 2021

37. OECD. Conversion rates - Purchasing power parities (PPP). Organization for Economic Co-operation and Development. 2020. http://data.oecd.org/ conversion/purchasing-power-parities-ppp.htm. Accessed 5 Jun 2020.

38. Wahlberg A, Rööst M, Haglund B, Högberg U, Essén B. Increased risk of severe maternal morbidity (near-miss) among immigrant women in Sweden: a population register-based study. BJOG. 2013;120(13):160511discussion 1612. https://doi.org/10.1111/1471-0528.12326.

39. Leppälä S, Lamminpää R, Gissler M, Vehviläinen-Julkunen K. Humanitarian migrant women's experiences of maternity care in Nordic countries: a systematic integrative review of qualitative research. Midwifery. 2020;80: 102572. https://doi.org/10.1016/j.midw.2019.102572.

40. Tanvig M. Offspring body size and metabolic profile - effects of lifestyle intervention in obese pregnant women. Dan Med J. 2014;61:B4893.

41. Briggs A. Economic evaluation and clinical trials: size matters. BMJ. 2000; 321(7273):1362-3. https://doi.org/10.1136/bmj.321.7273.1362.

42. Rogozinska E, Marlin N, Jackson L, Rayanagoudar G, Ruifrok AE, Dodds J, et al. Effects of antenatal diet and physical activity on maternal and fetal outcomes: individual patient data meta-analysis and health economic evaluation. Health Technol Assess. 2017;21(41):1-158. https://doi.org/10.331 0/hta21410.

43. Shepherd E, Gomersall JC, Tieu J, Han S, Crowther CA, Middleton P. Combined diet and exercise interventions for preventing gestational diabetes mellitus. Cochrane Database Syst Rev. 2017;11:CD010443. https:/ doi.org/10.1002/14651858.CD010443.pub3.

44. Muktabhant B, Lawrie TA, Lumbiganon P, Laopaiboon M. Diet or exercise, or both, for preventing excessive weight gain in pregnancy. Cochrane Database Syst Rev. 2015:(6):CD007145. https://doi.org/10.1002/14651858. CD007145.pub3.

45. Walker R, Bennett C, Blumfield M, Gwini S, Ma J, Wang F, et al. Attenuating pregnancy weight gain-what works and why: a systematic review and meta-analysis. Nutrients. 2018;10. https://doi.org/10.3390/nu10070944.

46. Schembre SM, Liao Y, Robertson MC, Dunton GF, Kerr J, Haffey ME, et al. Just-in-time feedback in diet and physical activity interventions: systematic review and practical design framework. J Med Int Res. 2018;20(3):e106. https://doi.org/10.2196/jmir.8701.

47. Hoomans T, Severens JL. Economic evaluation of implementation strategies in health care. Implement Sci. 2014;9(1):168. https://doi.org/10.1186/s13012014-0168-y.

48. Personcentrerad vård i Sverige [Person-centred care in Sweden] Gothenburg: University of Gothenburg: Swedish Association of Local Authorities and Regions; 2018.

49. Broekhuizen K, Simmons D, Devlieger R, van Assche A, Jans G, Galjaard S, et al. Cost-effectiveness of healthy eating and/or physical activity promotion in pregnant women at increased risk of gestational diabetes mellitus: economic evaluation alongside the DALI study, a European multicenter randomized controlled trial. Int J Behav Nutr Phys Act. 2018;15:23-018-0643-y.

50. Bailey C, Skouteris H, Harrison CL, Boyle J, Bartlett R, Hill B, et al. Cost effectiveness of antenatal lifestyle interventions for preventing gestational diabetes and hypertensive disease in pregnancy. Pharmacoecon Open. 2020; 4(3):499-510. https://doi.org/10.1007/s41669-020-00197-9.

\section{Publisher's Note}

Springer Nature remains neutral with regard to jurisdictional claims in published maps and institutional affiliations.

Ready to submit your research? Choose BMC and benefit from:

- fast, convenient online submission

- thorough peer review by experienced researchers in your field

- rapid publication on acceptance

- support for research data, including large and complex data types

- gold Open Access which fosters wider collaboration and increased citations

- maximum visibility for your research: over $100 \mathrm{M}$ website views per year

At BMC, research is always in progress.

Learn more biomedcentral.com/submissions 